03

\title{
Термокапиллярные структуры и разрыв нагреваемой пленки жидкости
}

\author{
(C) E.A. Чиннов \\ Институт теплофизики им. С.С. Кутателадзе СО РАН, Новосибирск, Россия \\ E-mail: chinnov@itp.nsc.ru
}

Поступило в Редакцию 18 марта 2019 г.

В окончательной редакции 12 апреля 2019г.

Принято к публикации 12 апреля 2019г.

Выполнены анализ и обобщение данных по формированию термокапиллярных структур и разрыву
нагреваемой пленки жидкости, стекающей по вертикальной поверхности. Показано, что взаимодействие
волн с термокапиллярными структурами типа $A$ приводит к увеличению критического теплового потока,
соответствующего разрыву пленки жидкости, по сравнению с известными из литературы данными (режим $B)$.

Ключевые слова: волны, термокапиллярные регулярные структуры, разрыв пленки жидкости, нагрев.

DOI: 10.21883/PJTF.2019.14.48024.17790

Интерес к пленочным течениям жидкости обусловлен как прикладной, так и научной значимостью этого класса течений. Течения пленок жидкости реализуются во многих технологических процессах и аппаратах.

К настоящему времени открыты разные механизмы формирования струй в нагреваемых пленках жидкости, выделено два термокапиллярных режима: $A$ и В [1]. Структуры типов $A$ и $B$ различаются уровнем плотности теплового потока, необходимого для их возникновения, величиной и характером зависимости расстояния между струями от плотности теплового потока и числа Рейнольдса $(\operatorname{Re}=\Gamma / \mu, \Gamma-$ удельный расход жидкости, $\mu$ - динамическая вязкость жидкости). В работах [2,3] обнаружено и исследовано формирование регулярных структур в термокапилляром режиме $A$ на поверхности гладкой пленки жидкости. Под действием термокапиллярных сил, напряженных против течения, происходило утолщение пленки. При достижении пороговой плотности теплового потока течение разделялось на вертикальные струи, следующие с определенным расстоянием $\Lambda$, и тонкую пленку между ними. Данные по формированию структур этого типа на поверхности пленок воды на протяженных нагревателях длиной $60 \mathrm{~mm}$ представлены в работе [4]. Теоретическое изучение и детальный анализ этого явления при $0.1 \leq \mathrm{Re} \leq 2$ выполнены в [5]. Установлено, что расстояние между струями практически не зависит от Re, а при фиксированном числе Марангони может даже убывать с ростом числа Рейнольдса.

В режиме $B$ струйное течение формировалось постепенно с ростом плотности теплового потока и расстояния от верхней кромки нагревателя. В работах $[1,4,6]$ показано, что в области довольно высоких тепловых потоков при $\operatorname{Re}>15$ расстояние между струями слабо зависит от числа Рейнольдса и длины пробега пленки. В [7] выполнено экспериментальное исследование формирования термокапиллярных структур при малых числах Рейнольдса до $\operatorname{Re}=0.1$. Показано, что поперечный размер структур определяется капиллярной постоянной и не зависит от вязкости жидкости.

Особенности формирования структур на поверхностях нагреваемой и изотермической пленок жидкости рассмотрены в работах [8-10].

Исследование динамики разрыва при помощи волоконно-оптического датчика выполнено в работе [11]. Влияние смачиваемости подложки на термокапиллярный разрыв пленки жидкости рассмотрено в [12]. В работе [13] термокапиллярный разрыв пленки исследован при изменении в широком диапазоне чисел Рейнольдса и размеров нагревателя.

Целью настоящей работы являются анализ и обобщение данных по формированию термокапиллярных структур и разрыву нагреваемой пленки жидкости, стекающей по вертикальной поверхности, при изменении числа Рейнольдса от 0.1 до 500.

На основании анализа опытных данных по гидродинамике течения нагреваемой пленки жидкости установлено, что структуры типа $A$ наблюдаются в диапазоне чисел Рейнольдса от 0.1 до 150. Они возникают на поверхности пленки жидкости при достижении порогового значения плотности теплового потока. При появлении структур в режиме $A$ в верхней части нагревателя зарегистрированы высокие градиенты температуры до $10-15 \mathrm{~K} / \mathrm{mm}$. На поверхности нагревателя реализовалось граничное условие, близкое к $T=$ const. В условиях развитого волнового течения термокапиллярные структуры типа $A$ формировались в остаточном слое пленки жидкости после прохождения фронта трехмерной волны. Структуры существовали ограниченный период времени и взаимодействовали с фронтом следующей волны, преобразуясь в струи, которые двигались вдоль нагревателя, изменяя направление (рис. 1).

В режиме $B$ формирование струйного течения происходило постепенно с ростом теплового потока и расстояния от верхней кромки нагревателя (рис. 1). 
Структуры типа $B$ зарегистрированы в диапазоне чисел Рейнольдса от 0.1 до 500. На поверхности нагревателя реализовалось граничное условие $q=$ const, а градиенты температуры на поверхности пленки не превышали $1 \mathrm{~K} / \mathrm{mm}$.

При определенных условиях (достаточно высокая плотность теплового потока, протяженный размер нагревателя и промежуточное граничное условие между $q=$ const и $T=$ const) на поверхности пленки могло существовать два типа структур (рис. 1).

Под действием термокапиллярных сил, направленных от более горячих областей к холодным, росла деформация поверхности пленки. В результате при увеличении плотности теплового потока происходил разрыв пленки жидкости. При формировании структур типа $A$ разрыв пленки жидкости происходил в верхней части нагревателя, где регистрировались максимальные деформации поверхности пленки, а при формировании структур типа $B-$ в нижней части нагревателя.

Обобщение опытных данных по тепловому потоку, соответствующему формированию структур в режиме $A$, выполнено в виде зависимости критерия $K m_{A}^{*}$ от $\operatorname{Re}($ рис. $2, a)$. Критерий $K m_{A}^{*}$ характеризует удельную тепловую мощность $W_{A} / B$, выделенную на нагревателе, на прогрев пленки

$$
\begin{aligned}
K m_{A}^{*} & =-q_{A}\left(\sigma_{T} /\left(c \rho^{2} g^{2 / 3} v^{5 / 3}\right)\right) L / l_{v}=-q_{A} L \sigma_{T} /\left(c \rho^{2} g v l_{v}^{2}\right) \\
& =-W_{A} \sigma_{T} /\left(B c \rho^{2} g v l_{v}^{2}\right)
\end{aligned}
$$

где $B$ - ширина нагревателя, $c-$ теплоемкость жидкости, $g$ - ускорение свободного падения, $L-$ длина нагревателя, $l_{v}=\left(v^{2} / g\right)^{1 / 3}-$ масштаб вязкогравитационного взаимодействия, $q_{A}$ - плотность теплового потока, при которой происходит формирование структур в режиме $A, v-$ кинематическая вязкость жидкости, $\sigma_{T}=\partial \sigma / \partial T-$ производная коэффициента поверхностного натяжения по температуре, $\rho$ - плотность жидкости.

В качестве рабочих жидкостей использовались вода, перфтортриэтиламин (МД-ЗФ) и диэлектрическая жидкость FC-72. Их свойства представлены в таблице.

Условие формирования структур в режиме $A$ на поверхности пленки жидкости описывается следующим

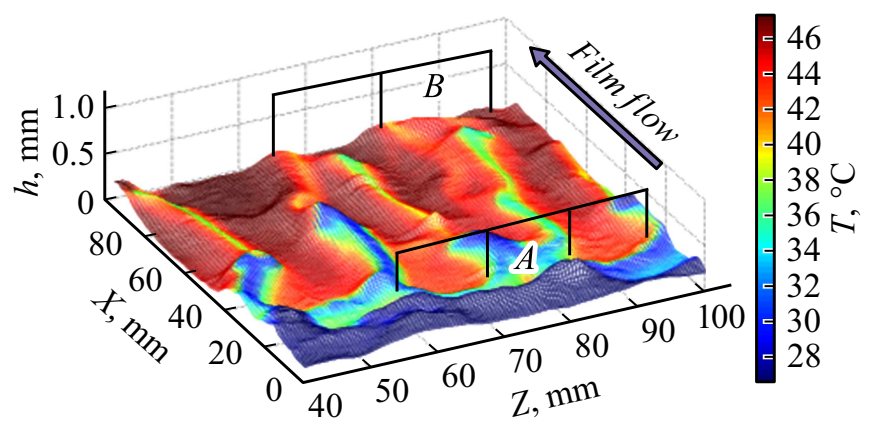

Рис. 1. Трехмерное распределение толщин и температур на поверхности пленки жидкости. $\mathrm{Re}=50$.
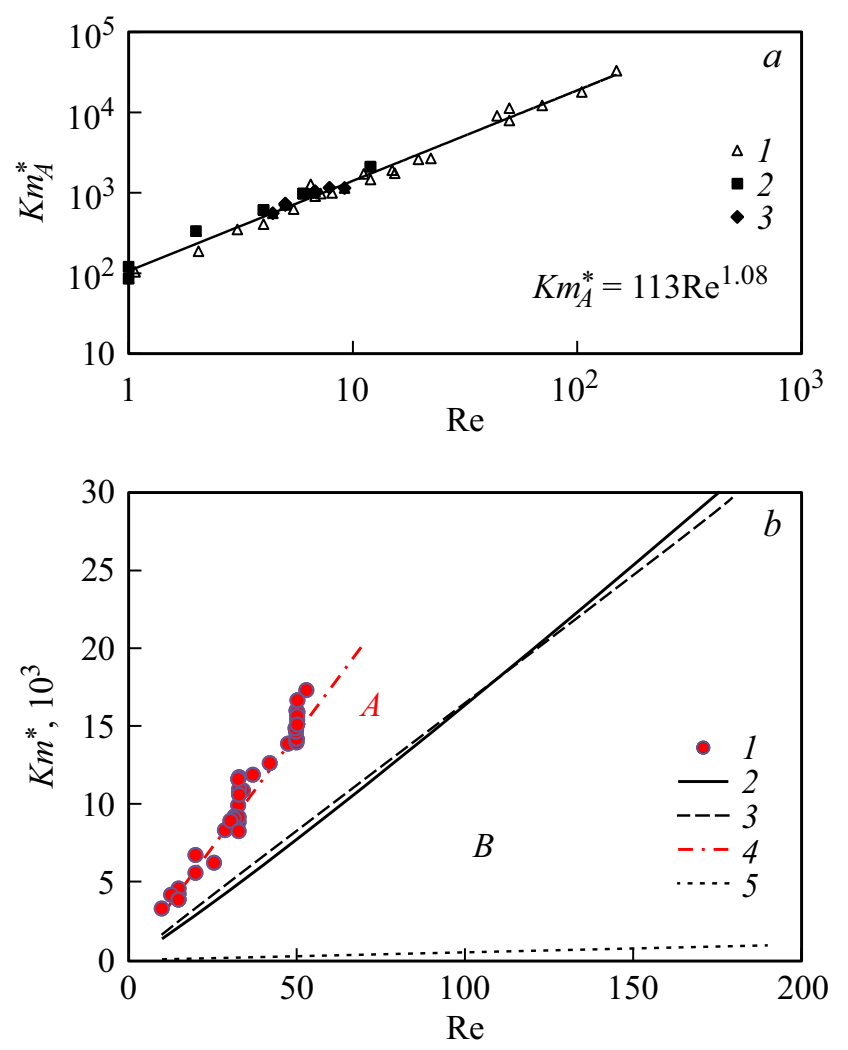

Рис. 2. Обобщение опытных данных по формированию термокапиллярных структур и разрыву пленки жидкости. $a-$ данные по формированию структур в режиме $A$. Используемые жидкости: 1 - вода, 2 - МД-3Ф [2], 3 - FC-72 [1]. $b$ - данные по формированию термокапиллярных структур и разрыву пленки. 1 - экспериментальные данные по разрыву пленки воды после формирования структур типа $A, 2$ - зависимость (2), 3 - зависимость (3), 4 - зависимость (4), 5 - линия, выше которой структуры $B$ становятся различимыми.

Физические свойства используемых жидкостей

\begin{tabular}{c|c|c|c|c|c}
\hline $\begin{array}{c}\text { № } \\
\text { п/п }\end{array}$ & Жидкость & $T,{ }^{\circ} \mathrm{C}$ & $\rho, \mathrm{kg} / \mathrm{m}^{3}$ & $\begin{array}{c}\mu \cdot 10^{3} \\
\mathrm{~Pa} \cdot \mathrm{s}\end{array}$ & $\begin{array}{c}\sigma \cdot 10^{3}, \\
\mathrm{~N} / \mathrm{m}\end{array}$ \\
\hline 1 & Вода & 20 & 1000 & 1 & 73 \\
2 & дистиллированная & & & & \\
3 & ІС-72 & 20 & 1688 & 0.743 & 12.6 \\
& МД-3Ф & 30 & 1720 & 0.932 & 11.6
\end{tabular}

соотношением (сплошная линия на рис. $2, a)$ :

$$
K m_{A}^{*}=113 \operatorname{Re}^{1.08} .
$$

На рис. 2, $b$ приведены данные по разрыву пленки жидкости при формировании структур $A$ и $B$. При развитии на поверхности пленки жидкости только структур $B$, что выполняется при условии $q=$ const на поверхности нагрева, разрыв происходил всегда в нижней части нагревателя между сформировавшимися струями. C увеличением плотности теплового потока в нижней части нагревателя происходило резкое увеличение 


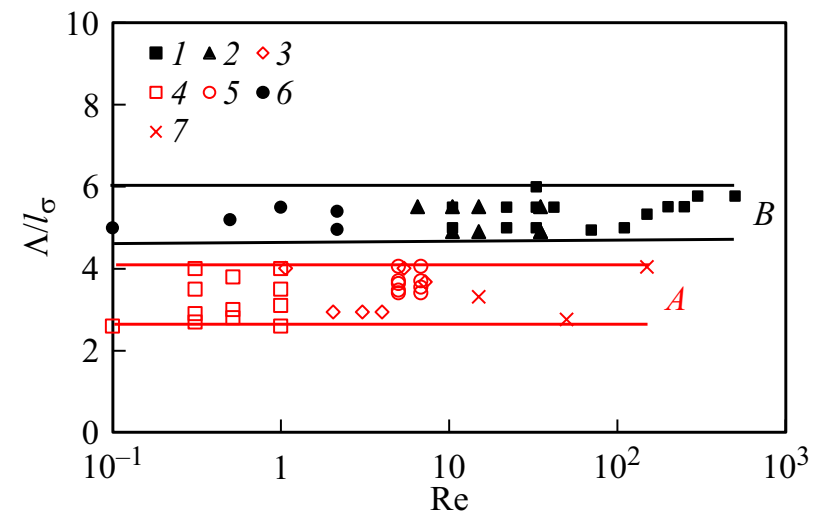

Pис. 3. Обобщение опытных данных по безразмерному расстоянию между струями термокапиллярных структур: 1 структуры $B$, вода [7]; 2 - структуры $B$, FC-72 [1]; 3 - структуры $A$, вода [4]; 4 - структуры $A$, данные [5]; 5 - структуры $A$, FC-72 [1]; 6 - структуры $B$, раствор глицерина в воде [7]; 7 - структуры $A$, вода. $l_{\sigma}$ - капиллярная постоянная.

деформации пленки жидкости, что и приводило к ее разрыву (появлению первого устойчивого сухого пятна). На рис. 2, $b$ представлено обобщение данных для разных типов жидкости. Данные для разрыва в режиме $B$ обобщаются зависимостью из работы [14]:

$$
K m_{c r B}^{*}=165 \operatorname{Re} .
$$

При формировании структур в режиме $A$ на поверхности пленки жидкости плотность теплового потока, соответствующая разрыву, существенно возрастала, так как в результате взаимодействия трехмерных волн с термокапиллярными структурами возрастала их амплитуда [15]. Гидродинамические волны распространялись по сформировавшимся на поверхности жидкости струям, которые перемещались в поперечном направлении (рис. 1). Менялся характер разрыва пленки. Возникающие сухие пятна замывались жидкостью. Данные для разрыва в режиме $A$ (появление первого устойчивого пятна), полученные для воды при разных начальных температурах, обобщаются следующей зависимостью:

$$
K m_{c r A}^{*}=290 \mathrm{Re} .
$$

Интересным представляется факт близкого расположения зависимостей (2) и (3) на рис. 2, $b$. Видно, что при $\operatorname{Re}<100$ сначала (при меньших тепловых потоках) формируются структуры в режиме $A$ (зависимость 2), а затем (при больших тепловых потоках) может происходить разрыв в режиме $B$ (зависимость 3 ). В выполненных экспериментах при $\operatorname{Re}<50$ на нагревателе длиной по потоку $100 \mathrm{~mm}$, где выполнялось промежуточное граничное условие между $q=$ const и $T=$ const, pазрыв всегда происходил в режиме $A$ в верхней части нагревателя при более высоких тепловых потоках. Влияние возмущений, возникающих при взаимодействии волн со структурами типа $A$, на разрыв пленки жидкости при $\operatorname{Re}>100$ нуждается в дополнительных исследованиях.
На рис. 3 представлено обобщение существующих экспериментальных и теоретических данных по безразмерному расстоянию между струями наблюдаемых структур. Выделены области термокапиллярных структур $A$ и $B$. Видно, что безразмерные расстояния между струями в обоих случаях автомодельны относительно числа Рейнольдса.

Таким образом, выполнено обобщение данных по формированию термокапиллярных структур и разрыву нагреваемой пленки жидкости при изменении числа Рейнольдса от 0.1 до 500. Показано, что расстояния между струями термокапиллярных структур для этих режимов различаются в 1.5 раза и не зависят от числа Рейнольдса. Установлено, что формирование метастабильных термокапиллярных структур типа $A$ в верхней части нагревателя оказывает влияние на величину критического теплового потока, соответствующего разрыву пленки жидкости. Показано, что величина критического теплового потока возрастает с увеличением числа Рейнольдса пленки и при $\mathrm{Re}<50$ существенно превосходит данные по разрыву в отсутствие термокапиллярных структур типа $A$. Можно заключить, что обнаружен новый метод воздействия на пленочное течение, приводящий к повышению его устойчивости к разрыву. Результат является важным, так как обнаруженный способ повышения устойчивости пленок жидкости может быть использован в промышленных установках.

\section{Финансирование работы}

Исследование разрыва пленки жидкости и обобщение данных выполнены за счет гранта Российского научного фонда (соглашение № 18-19-00407), исследование термокапиллярных структур в режиме $A$ (дополнительные данные эксперимента) проведено в рамках государственного задания (АААА-А17-117022850022-0).

\section{Список литературы}

[1] Чиннов E.A., Кабов О.А. // ПМТФ. 2003. Т. 44. № 5. С. 128 137.

[2] Kabov O.A., Chinnov E.A. // Russ. J. Eng. Thermophys. 1997. V. 7. N 1-2. P. 1-34.

[3] Кабов О.А. // Теплофизика и аэромеханика. 1998. Т. 5. № 4. C. $597-602$.

[4] Чиннов E.A. // Теплофизика и аэромеханика. 2009. Т. 16. № 1. C. 69-77.

[5] Frank A.M., Kabov O.A. // Phys. Fluids. 2006. V. 18. N 3. P. 032107 (1-10).

[6] Чиннов Е.А., Харламов С.М., Сапрыкина А.В., Жуковская O.B. // Теплофизика и аэромеханика. 2007. Т. 14. № 2. C. $249-255$.

[7] Шатский Е.Н., Чиннов Е.А., Зайцев Д.В., Семенов А.А., Кабов О.А. // Письма в ЖТФ. 2017. Т. 43. В. 23. С. 69-76.

[8] Aktershev S.P., Alekseenko S.V. // Int. J. Multiphase Flow. 2019. V. 114. P. 115-127. 
[9] Алексеенко С.В., Бобылев А.В., Гузанов В.В., Маркович Д.М., Харламов С.М. // Письма в ЖТФ. 2014. Т. 40. B. 22. C $97-104$.

[10] Бобылев А.В., Гузанов В.В., Харламов С.М., Квон А.З., Маркович Д.М. // Письма в ЖТФ. 2017. Т. 43. В. 15. С. 19 27.

[11] Zaitsev D.V., Rodionov D.A., Kabov O.A. // Micrograv. Sci. Technol. 2007. V. 19. N 3/4. P. 100-103.

[12] Зайщев Д.В., Кириченко Д.П., Кабов О.А. // Письма в ЖТФ. 2015. Т. 41. В. 11. С. 79-85.

[13] Зайцев Д.В., Семенов А.А., Кабов О.А. // Теплофизика и аэромеханика. 2016. Т. 23. № 4. С. 649-652.

[14] Чиннов Е.А., Шарина И.А. // Теплофизика и аэромеханика. 2008. T. 15. № 1. C. 121-130.

[15] Chinnov E.A. // Interfacial Phenom. Heat Transfer. 2018. V. 6. N 1. P. 89-97. 